\title{
QUASI-EXPERIMENT IN THE EDUCATIONAL REALITY
}

\author{
MARIANA SIROTOVÁ \\ Department of Pedagogy, University of ss. Cyril and Methodius in Trnava \\ Nám. J. Herdu 2, 91701 Trnava, Slovak Republic \\ E-mail address: mariana.sirotova@ucm.sk \\ ORCID ID: https://orcid.org/0000-0003-1599-9702 \\ VERONIKA MICHVOCÍKOVÁ \\ Department of Pedagogy, University of ss. Cyril and Methodius in Trnava \\ Nám. J. Herdu 2, 91701 Trnava, Slovak Republic \\ E-mail address: veronika.michvocikova@ucm.sk \\ ORCID ID: https://orcid.org/0000-0003-4199-7225

\section{KRZYSZTOF MARIUSZ RUBACHA} \\ Department of Pedagogy, University of ss. Cyril and Methodius in Trnava \\ Nám. J. Herdu 2, 91701 Trnava, Slovak Republic \\ E-mail address: krzysztof.rubacha@ucm.sk \\ ORCID ID: https://orcid.org/0000-0002-7447-6736
}

\begin{abstract}
Aim. The main aim of the study is a presentation of the results of a quasi-experiment related to using a serious game in the preparation phase of supervised teaching practice as well as during its completion.

Methods. The main method of the study is a quasi-experiment with the factor rotation technique. The method comprised two phases with two unequal groups of surveyed university students. In the first phase, the experimental influence was investigated in the first group and the second group served as the control group (to compare the results). In the second phase, the groups were switched around in the quasi-experiment; the control group became the experimental group and vice versa.

Results. The presented study has a theoretical-empirical character. In the theoretical part, the characteristics of quasi-experiment and its use are briefly discussed. In the empirical part, the quasi-experiment is applied to the educational reality of future teachers. Supervised practice teaching is an important part of the university education of future teachers. Using a serious game therein is a positive element also when it comes to the development of students' approach towards supervised teaching practice.

Conclusion. Quasi-experiment is used as an experimental method for verification of examined reality. In the educational reality, its realisation is more difficult because it
\end{abstract}


is a more demanding environment than a laboratory one. By realising the quasi-experiment, the theoretical supposition about the positive influence of serious games on the development of a university student's personality can be confirmed.

Key words: educational reality, factor rotation technique, quasi-experiment, university education, university students

\section{INTRODUCTION}

$\mathrm{P}$ re-graduate preparation of a teacher and the teaching practice completed during this preparation are important factors influencing the teacher's future profession and the development of his or her professional competencies. It is, therefore, necessary to pay attention to supervised teaching practice not only from the aspect of its practical realisation but also from the research point of view. In our opinion, research related to this issue should be connected with the study of gradual integration of the virtual dimension and its innovative possibilities within teachers' practical training. We see computer games, which are highly popular among young people today, as part of the virtual dimension. An educational computer game (referred to as a serious game) can be a tool that supports the transformation of practical experience and theoretical knowledge in the development of future teachers' professional competencies. Currently, however, there is no such game. We are of the opinion that simulation computer games should be incorporated into educational processes. They are beneficial not only for the advancement of knowledge but also for students' psychomotor development. They bring students a new way of advancing their creativity and bridging the theoretical prerequisites of the study programme with the teaching practice. This was the reason why a team of experts from the Department of Pedagogy at the Philosophical Faculty of the University of Cyril and Methodius in Trnava in cooperation with theFaculty of Natural Sciences of University of Ss. Cyril and Methodius in Trnava. The team of experts participated on a project named KEGA 015UCM -4/2018 "Supervised Teaching Practice for University Students with the Support of the Virtual Dimension."

\section{Theoretical outline of the experimental method and additional methods of collecting data}

Experimenting is natural to people and so are their attempts to confirm the correctness of their decisions. In scientific research, it is the experiment that is seen as the tool for verification of new theories and decisions derived from them. As Maršálová states, "the experiment is a generally accepted scientific method attempting to determine regularities in the occurrence of certain phenomena" (as cited in Švec et al., 1998, p. 173). The hallmark of this method is the fact that if you strictly adhere to the rules of its realisation, you learn not only about the relationships between certain phenomena but also what causes their relationship, what determines them and why they occur. The attempt of the experimental 
method to confirm or disprove theoretically or empirically justified assumptions and hypotheses related to cause-effect relationships is important not only for the building of the theoretical system of pedagogy but also for practical reasons of optimising and improving educational processes (Maršálová, as cited in Švec et al., 1998, p. 173). The experiment is a scientific method that lies in the possibility of manipulating the variables. Miroslav Chráska (2007) states that during an experiment, we manipulate at least one independent variable. According to the chosen experimental plan, the experimenter works with variables, which allows him or her to discover deeper causal relationships than those that would be possible by using other scientific methods. In their work, however, experimenters systematically utilise the capabilities of other scientific methods for collecting necessary information related to the change in behaviour or features of the experiment's subjects. Pedagogical reality is a much more difficult environment for the realisation of an experiment than is, for example, a physical or biological reality, and for this reason, conducting an experiment in this field is highly challenging. Each pedagogical situation is unique and cannot be repeated. Independent variables are not isolated but form mutually conditioned interactions with other factors of the educational process and a random choice of the experiment subjects would be very difficult considering the organisational structure of a school or an educational system. An experiment in which the researcher cannot choose subjects is called the quasi-experiment. The majority of experimental studies in pedagogy are quasi-experiments (Gavora, Koldeková, Dvorská, Pekárová, \& Moravčík, 2010).

\section{A serious game from the perspective of the factor rotation technique in a quasi-experiment}

The presented theoretical outline introduced characteristics of the experimental method and other supplementary methods for collecting data that are necessary for an optimal realisation of an experiment or quasi-experiment. Considering the issue at hand from the perspective of the quasi-experiment, our focus was to assess the efficiency of a serious game (educational digital game) used during supervised teaching practice. Our main criterion was the level of achieved results in an educational process, where the result was a particular expression of the change in knowledge, ability and skill related to a student's personality. Considering the extent of the issue, it is necessary to focus mainly on two basic categories when trying to evaluate the results of an educational process. The first category is represented by a student's ability to acquire theoretical knowledge and the second category by the student's ability to implement the knowledge into solving model situations from a professional reality. Based on the goal of our project KEGA 015UCM - 4/2018 "Supervised Teaching Practice for University Students with the Support of a Virtual Dimension," we have decided to study the second category representing the implementation of knowledge into supervised teaching practice. 


\section{MATERIALS AND METHODS}

\section{Causality and hypotheses of the quasi-experiment}

Causality is the core of an experiment or quasi-experiment and represents the causal conditionality. In the realisation of the experimental method, it is necessary to determine a cause - an occurrence whose causal influence we want to observe and a measurable consequence for the verification of set hypotheses. In the first step, an occurrence must be recorded in our quasi-experiment, it is represented by the independent variable. The second step is to determine the consequence - the dependent variable, i.e. an effect caused by the experimental influence. In our quasi-experiment, the independent variable is represented by playing a serious game. To ensure the highest possible objectivity, we have defined the dependent variable as a degree of implemented knowledge in solving a model situation from a professional reality.

The goal of our quasi-experiment is to assess the effectiveness of a serious game. We would like to find out if playing the game benefits the realisation of supervised teaching practice and improves the implementation of knowledge in solving model situations from a professional reality. We would also like to collect students' subjective opinions on the game itself. Considering the set goal, we have chosen two hypotheses:

Hypothesis No. 1:

We expect a statistically significant difference in students' positive evaluation of supervised teaching practice. We suppose that students educated with the use of the serious game evaluate the realisation of supervised teaching practice more positively than students educated without the game.

Hypothesis No. 2:

We expect a statistically significant difference in the implementation of knowledge in solving model situations from a professional reality. We suppose that students educated with the use of the serious game suggest more solutions to a model situation than students educated without the game.

Methods and subjects in the process of conducting the quasi-experiment

In our quasi-experiment, we have used the factor rotation technique. The cornerstone of this technique is the exchange of position between the experimental and the control groups during the experiment. The exchange is caused by working with the independent variable. Both groups are exposed to the experimental influence in different phases, which changes their position from the experimental group to the control group and vice versa. The quasi-experiment itself has two phases. A pretest and a posttest measuring of subjects' attributes in two categories is performed at the beginning as well as during the experiment after the groups changed their position. Table No. 1 introduces a graphic illustration of the experimental plan using a pretest and a posttest in the factor rotation technique. 
Table 1

The experimental plan of the factor rotation technique

\begin{tabular}{|c|c|c|}
\hline & group of subjects A & group of subjects B \\
\hline 1st phase & pretest measuring of & pretest measuring of \\
\hline group $A$ is the & subjects' attributes $m_{A 1}$ & subjects' attributes $m_{\mathrm{B} 1}$ \\
\hline \multirow[t]{2}{*}{ experimental group } & posttest measuring of & posttest measuring of \\
\hline & subjects' attributes $m_{A 2}$ & subjects' attributes $m_{\mathrm{B} 2}$ \\
\hline 2nd phase & pretest measuring of & pretest measuring of \\
\hline group B is the & subjects' attributes $m_{\mathrm{A} 3}$ & subjects' attributes $m_{B 3}$ \\
\hline \multirow[t]{2}{*}{ experimental group } & posttest measuring of & posttest measuring of \\
\hline & subjects' attributes $m_{\mathrm{A} 4}$ & subjects' attributes $m_{B 4}$ \\
\hline
\end{tabular}

Source: own research

We have also used supplementary methods: the questionnaire and the content analysis of text documents. To collect information about the respondents' subjective views of the educational computer game, we used a questionnaire. In this questionnaire, we asked questions regarding the playfulness and effectiveness of the serious game as well as the students' views of the supervised teaching practice itself. The second supplementary method was the content analysis of text documents. In our quasi-experiment, the text documents were represented by solutions to model situations. To analyse the solutions to model situations, we chose the most frequently used quantification procedure for determining the frequency of occurrence related to an analytical category in a text. This quantification procedure is the most suitable for processing written solutions to a model situation. In the first phase, we set the analytical categories of content, which are fixed indicators used for sorting recording units, and in our quasi-experiment, these were the possible correct solutions to the model situation. As stated in the theoretical outline, the recording units are significant elements of content represented by a single word, a phrase, a term, a group of phrases, a sentence or a group of sentences containing a certain informative value. In the analysis of model situations in our quasi-experiment, the recording units were represented by the most frequently occurring ideas and solutions to the model situation in the form of text passages (groups of sentences), which were not written in the same words but their information value or meaning was identical. These were further assigned to analytical categories, which referred to correct solutions to the model situation; hence, the number of recording units represented the number of adequate solutions related to a subject.

The factor rotation technique, as is the case with other techniques of the experiment or quasi-experiment, has its positives and negatives. One of the positives is that there is no need for the researcher to work with equal groups of subjects and to control the unwanted factors influencing the realisation of the experiment or quasi-experiment. This was the main reason why we chose 
this technique. In university education, it is difficult to ensure group equality in a quasi-experiment. Fixed placement of students into groups within one subject of study does not allow us to use the intentional selection of subjects, which seems to be most suitable when using the technique of parallel groups in a quasi-experiment. The intentional selection is performed based on determining relevant attributes, i.e. those attributes of the basic pool that are important for given research; nevertheless, since we used the factor rotation technique, its selection was not necessary.

Our quasi-experiment was conducted during the winter semester of the academic year 2019/2020 as part of the subject named Supervised Teaching Practice. The subjects of our quasi-experiment were students of the study programme "Teaching of Academic Subjects". The first group (A) comprised third-year students studying the programme Teaching of Academic Subjects (undergraduate level). The second group (B) comprised first-year students (postgraduate level) in the study programme Teaching of Academic Subjects (various subjects). Table No. 2 shows the division of subjects according to groups, age and gender.

Table 2

Characterisation of the subjects in the quasi-experiment

\begin{tabular}{|c|c|c|c|c|c|c|c|c|c|c|c|c|}
\hline \multirow[t]{3}{*}{ group } & \multicolumn{4}{|c|}{ gender indicator } & \multicolumn{3}{|c|}{ age indicator } & \multirow[b]{2}{*}{$21-25$} & \multirow{2}{*}{\multicolumn{2}{|c|}{ over 26}} & & \multirow[b]{2}{*}{ average } \\
\hline & male & & female & & totol & below 20 & & & & & & \\
\hline & number & $\%$ & number & $\%$ & total & number & $\%$ & number & $\%$ & number & $\%$ & age \\
\hline A & 5 & 36 & 9 & 64 & 14 & 0 & 0 & 14 & 100 & 0 & 0 & 21 \\
\hline B & 7 & 47 & 8 & 53 & 15 & 0 & 0 & 14 & 96 & 1 & 4 & 22 \\
\hline
\end{tabular}

Source: own research

The quasi-experiment was conducted during one semester within the subject Supervised Teaching Practice. This subject is taught via seminars and its objective is to introduce students to the issue of supervised teaching practice realisation, in which they continuously participate during the semester. In the case of undergraduate students, this is an observational teaching practice (observation of classes). In the case of postgraduate students, it is a continuous performance-based teaching practice. In the beginning, students were acquainted with the goal of the subject, its organisation as well as the conditions for gaining credits for the subject. To obtain credits, students were required, among other things, to process four model situations and, based on the position of the group in the quasi-experiment, also play our serious game.

Before the quasi-experiment was performed, we prepared two syllabuses for the subject of Supervised Teaching Practice. The first syllabus (for group 
A) included playing our serious game during the first six seminars, followed by discussions of methods related to the model situations and the realisation of supervised teaching practice. The syllabus for group B also involved discussions of methods related to model situations and playing the game but in the reverse order compared to group A. We have had several years of experience with the discussions of methods to model situations as well as with the quasi-experiment which was, in the past, conducted using the technique of parallel groups as well as the factor rotation technique. In our research, the factor rotation technique enables us to obtain objective results.

The analysis and interpretations of the quasi-experiment findings

The factor rotation technique enables us to determine the level of increase in the production of adequate solutions to model situations from a professional reality suggested by the subjects of quasi-experiment in three areas (Chráska, 2007).

The first area relates to the increase in production of adequate solutions to model situations from a professional reality caused by the experimental influence, which can be expressed as:

$$
\left(m_{A 2}-m_{A 1}\right)+\left(m_{B 4}-m_{B 3}\right)
$$

The level of increase without the experimental influence can be determined in a similar way:

$$
\left(m_{B 2}-m_{B 1}\right)+\left(m_{A 4}-m_{A 3}\right)
$$

The change caused by the independent variable (the experimental influence) can be expressed in the following way:

$$
\left[\left(m_{A 2}-m_{A 1}\right)+\left(m_{B 4}-m_{B 3}\right)\right]-\left[\left(m_{B 2}-m_{B 1}\right)+\left(m_{A 4}-m_{A 3}\right)\right]
$$

In the analysis, we used the sums of arithmetic means related to the number of adequate solutions to model situations; their final difference was used to determine the change caused by the independent variable, which was in our case the use of serious game.

In our quasi-experiment, the students' ability to implement acquired knowledge in solving model situations from a professional reality was determined as the examined category of the dependent variable. Hypothesis number 2 assumes a statistically significant difference and for its statistical verification, we chose the F-test and the level of significance 0.01. Through EXCEL 97 software and its statistical functions, we calculated the testing criterion F and compared it to the critical values of the F's distribution in statistical tables. We were trying to establish whether the difference in the number of suggested adequate solutions to model situations when the groups were in the phase of the experimental influence was statistically significant. The results are given according to the position of the (experimental) group. 
Table 3

The increase in the production of solutions to a model situation as a result of the experimental influence

\begin{tabular}{ccllll} 
& \multicolumn{2}{l}{$\operatorname{group} A$} & \multicolumn{2}{l}{$\operatorname{group~B}$} \\
\hline 1. & st phase & $m_{\mathrm{A} 1}$ & 2.29 & $\mathrm{x}$ & \\
& & $m_{\mathrm{A} 2}$ & 5.57 & $\mathrm{x}$ & \\
2. & \multirow{2}{*}{ nd phase } & $\mathrm{x}$ & & $m_{\mathrm{B} 3}$ & 2.53 \\
& & $\mathrm{x}$ & $m_{\mathrm{B} 4}$ & 5.67 \\
\hline
\end{tabular}

Source: own research

Table 4

The increase in the production of solutions to a model situation without the experimental influence

\begin{tabular}{ccllll} 
& \multicolumn{2}{c}{ group A } & \multicolumn{2}{c}{ group B } \\
\hline 1. & st phase & $\mathrm{x}$ & $m_{\mathrm{B} 1}$ & 2.20 \\
2. & \multirow{2}{*}{ nd phase } & $\mathrm{x}$ & $m_{\mathrm{B} 2}$ & 3.00 \\
& & $m_{\mathrm{A} 3}$ & 2.43 & $\mathrm{x}$ & \\
\hline
\end{tabular}

Source: own research

In the pretest identification of the subjects' characteristics during the first phase of the quasi-experiment, the arithmetic mean of the number of suggested adequate solutions to model situations in group A was 2.29 and in group B 2.53. The low difference between the arithmetic means of both groups (0.24) confirms the similarity of the subjects' characteristics in both groups at the beginning of the quasi-experiment. As stated in the theoretical outline, the factor rotation technique does not require the equality of the groups. If the characteristics of subjects in the groups are equal, we can expect that the differences in the results of the posttest measuring of subjects' characteristics in the experimental phase be caused by the independent variable in the second category as well.

While determining the increase in production of adequate solutions to model situations caused by the experimental influence using the factor rotation technique, the decisive element is the sum of differences between the pretest and posttest measuring of the subjects' characteristics in the respective phases of the quasi-experiment. The increase in production of adequate solutions caused by the experimental influence represents the mathematical value 6.42 and the increase in production of adequate solutions without the experimental influence is represented by the value of 1.66 . These values express the average number of suggested adequate solutions to model situations in the respective phases of the quasi-experiment. 
Table 5

The numerical expression of the change caused by the independent variable

\begin{tabular}{ccccccc}
\multicolumn{4}{c}{ group A } & group B \\
\hline 1. st & phase & $m_{A 1}$ & 2.29 & $m_{\mathrm{B} 1}$ & 2.20 \\
& & & $m_{A 2}$ & 5.57 & $m_{\mathrm{B} 2}$ & 3.00 \\
2. & \multirow{2}{*}{ nd } & phase & $m_{\mathrm{A} 3}$ & 2.43 & $m_{\mathrm{B} 3}$ & 2.53 \\
& & $m_{\mathrm{A} 4}$ & 3.29 & $m_{B 4}$ & 5.57 \\
\hline
\end{tabular}

Source: own research

What is important, however, is the difference between the sums of increases in the production of adequate solutions to model situations caused by the experimental influence and increases of adequate solutions obtained without the experimental influence. Numerically, this difference is 4.76 (arithmetic mean of the number of results acquired during pretest and posttest measuring of the subjects' characteristics). This difference confirms the correctness of our second hypothesis related to the implementation of acquired theoretical knowledge in solving model situations from a professional reality, meaning that students educated through our serious game suggest more solutions to model situations than students educated without the game. For statistical verification of our hypothesis, we chose the F-test. We were trying to establish whether the difference in the number of suggested adequate solutions was statistically significant during the phase when the groups were in the position of the experimental group. The results are given according to the position of the (experimental) group.

Table 6

Values for the tested criteria $F$ of suggested adequate solutions in the phase of the experimental influence in group $A$

Pretest of Posttest of Pretest of Posttest of group A-mA1 group A-mA2 group B-mB1 group B-mB2

\begin{tabular}{lllll}
\hline $\begin{array}{l}\text { Pretest of } \\
\text { group A - mA1 }\end{array}$ & $\mathrm{x}$ & 0.94 & 0.04 & $\mathrm{x}$ \\
$\begin{array}{l}\text { Posttest of } \\
\text { group A - mA2 }\end{array}$ & 0.94 & $\mathrm{x}$ & $\mathrm{x}$ & 0.02 \\
$\begin{array}{l}\text { Pretest of } \\
\text { group B - mB1 }\end{array}$ & 0.04 & $\mathrm{x}$ & $\mathrm{x}$ & 0.86 \\
$\begin{array}{l}\text { Posttest of } \\
\text { group B - mB2 }\end{array}$ & $\mathrm{x}$ & 0.02 & 0.86 & $\mathrm{x}$ \\
\hline
\end{tabular}

Source: own research

Values of F-tests acquired in the pretest and posttest measuring of the number of adequate solutions to model situations in group A during the experimental influence (0.94) and in group B without the experimental influence $(0.86)$ and the value of F-tests (0.02) between groups A and B in the posttest measuring confirmed statistical significance in the production of adequate 
solutions to model situations based on the use of the serious game. The variances of both groups are statistically significant if the value of the F-test is lower than 0.05 .

Table 7

Values of the tested criteria $F$ of suggested adequate solutions during the phase of the experimental influence in group $B$

$$
\text { Pretest of Posttest of Pretest of Posttest of }
$$

group $\mathrm{A}-\mathrm{mA} 3$ group $\mathrm{A}-\mathrm{mA} 4$ group $\mathrm{B}-\mathrm{mB} 3$ group $\mathrm{B}-\mathrm{mB} 4$

\begin{tabular}{lcccc}
\hline $\begin{array}{l}\text { Pretest of } \\
\text { group A - mA3 }\end{array}$ & $\mathrm{x}$ & 0.75 & 0.43 & $\mathrm{x}$ \\
$\begin{array}{l}\text { Posttest of } \\
\text { group A - mA4 }\end{array}$ & 0.75 & $\mathrm{x}$ & $\mathrm{x}$ & 0.05 \\
$\begin{array}{l}\text { Pretest of } \\
\text { group B - mB3 }\end{array}$ & 0.43 & $\mathrm{x}$ & $\mathrm{x}$ & 0.37 \\
$\begin{array}{l}\text { Posttest of } \\
\text { group B - mB4 }\end{array}$ & $\mathrm{x}$ & 0.05 & 0.37 & $\mathrm{x}$ \\
\hline
\end{tabular}

Source: own research

Similar results were obtained in the second phase of the quasi-experiment when group B was in the position of the experimental group. Values of F-tests acquired in the pretest and posttest measuring of adequate solutions to model situations in group A without the experimental influence (0.75) and in group $B$ with the experimental influence (0.37) and the value of F-tests $(0.05)$ between groups A and B in the posttest confirmed statistical significance in the production of adequate solutions to model situations. Model situations were based on the use of the computer game during seminars for the subject of Supervised Teaching Practice.

By comparing the values of the calculated $\mathrm{F}$ criteria in the respective phases of the quasi-experiment between the groups of subjects (0.02 and 0.05$)$, we have confirmed a statistically significant difference in the production of adequate solutions to model situations in pretest and posttest measuring of the subjects' characteristics caused by the independent variable. This confirms our hypothesis No. 2, which prognosticated a statistically significant difference in the implementation of acquired theoretical knowledge in solving model situations from a professional reality, meaning that students educated through our serious game suggest more solutions to a model situation than students educated without the game.

\section{The results of the quasi-experiment}

University education flexibly reacts to ongoing changes in society through creating new study programmes, changing the content of the existing programmes, changing the methods of assessing educational results and students' work and changing the position as well as mutual relationships between the teacher and the student in the educational process of a univer- 
sity. The current age is characterised by an explosion of new knowledge and both its incorporation into study programmes and immediate practical usability require a new system of pre-graduate education. The requirements of the labour market are progressively higher and more demanding and if a graduate wants to find employment, having a solid theoretical knowledge without well-developed practical competencies often appears to be insufficient. In addition to professional competencies, employers require competencies related to critical and comparative thinking, problem-solving, creativity, teamwork, communicativeness, developed evaluation processes ensuring both adequacy in decision-making and flexibility in acting. Based on these facts, it is also necessary to change educational methods and didactic tools in the university educational process. Serious games seem to be an adequate supplementary tool for the development of professional as well as personal competencies necessary for the job of a future teacher. Today, young people often depend on modern information and communication technologies and social networks. This 'addiction' can be utilised in the educational process and, thus, help students to develop necessary competencies through digital games.

Performing our quasi-experiment, we have searched for answers that would confirm our theoretical supposition about the positive influence of serious games on the development of a university student's personality. We have focused on the implementation of theoretical knowledge in solutions to model situations from a professional reality. To increase the information value of our findings, we have used the factor rotation technique, which works with unequal groups. As a result, it was not necessary to control the factors influencing the realisation of the quasi-experiment. The disadvantage of this technique, however, is the rotation itself, meaning the order of the groups' position based on the experimental influence. However, based on the values of the calculated $\mathrm{F}$ criterion in both phases of the quasi-experiment, we can assume that the order of the groups' position based on the experimental influence did not negatively affect our findings.

In the second hypothesis, we predicted a statistically significant difference in the ability to apply theoretical knowledge to solving model situations from a professional reality, meaning that students educated through our serious game would suggest more solutions to a model situation than students educated without the game. Through statistical verification using F-tests, this hypothesis was confirmed. Students who used the serious game during their seminars suggested $59 \%$ more adequate solutions to model situations than students educated without the use of the game. We can, therefore, assume that the game influences, on the one hand, the development of the students' knowledge structure but also other competencies stated above, which are a necessary output of a university study. Another significant benefit is the formation of students' positive approach to supervised teaching practice, which is a basic precondition of an adequate realisation of the practice and the subsequent development of students' professional competencies. 
From the research point of view, we can see the serious game as a positive element also when it comes to the development of students' relationship towards supervised teaching practice. Through open-ended questions in our questionnaire, we asked students about their approach to supervised teaching practice as an obligatory part of their pre-graduate education. Based on the positive attitude of contemporary young people towards digital games, we assumed the game would influence positively the development of students' approach to supervised teaching practice. In our hypotheses No. 1, we predicted a significant percentage increase in the positive evaluation of supervised teaching practice realisation, meaning that students educated through our serious game would assess supervised teaching practice realisation more positively than students educated without the game.

Based on the sum of positive answers related to students' attitude towards supervised teaching practice, we could see that students' positive approach to the teaching practice went up by $67 \%$ when the game was incorporated into seminars. The most frequently stated advantage $(49 \%)$ of the teaching practice realisation incorporating the computer game was the possibility to practice substandard pedagogical situations that students most often viewed as problematic. Students' answers also included some negative views. However, universities could eliminate these downsides only partially. The most frequently stated downside was communication and relationship with the practice teacher. This problem was mentioned by $11 \%$ of students. Another downside closely connected to the practice realisation was pupils' discipline in the classroom. As many as $27 \%$ of student-trainees admitted that they had problems with maintaining pupils' discipline even in the presence of the practice teacher. Nevertheless, in the end, a $67 \%$ increase in the positive evaluation of supervised teaching practice after incorporating our serious game into education can be considered sufficient. We can, thus, consider hypothesis No. 1 confirmed as well.

\section{CONCLUSION}

There are several positive outcomes in favour of incorporating serious games into university education. Their implementation improves the quality and efficiency of the study, which depends not only on the teacher's work but mainly on students' reactions. Students should be able to not merely acquire new knowledge but to utilise it in playing the serious game as well and, subsequently, to critically confront it with their own experiences from supervised teaching practice. This would facilitate the creation of favourable conditions for the development of professional competencies necessary for their future teaching job. 


\section{ACKNOWLEDGEMENTS}

The study is a part of scientific project solving - KEGA 015UCM - 4/2018 "Pedagogická prax vysokoškolských študentov s podporou virtuálnej dimenzie."

\section{REFERENCES}

[1] Chráska, M. (2007). The methods of pedagogical research - qualitative research. Praha: Grada.

[2] Danek, J. (2019). Pedagogical Practice - Position, contribution and importance in the process of preparing of future teachers. In: Slavonic Pedagogical Studies Journal. 8 (1), 31-41.

[3] Gabidullina, F. I., Korganbekov, S. B., Makarova, F. M., Zakirov, A. R., \& Kaymova, F. G. (2019). Concept «teacher» in language consciousness of students of philological faculty. In: XLinguae, 12 (3), $45-54$.

[4] Gavora, P., Koldeková, L., Dvorská, D., Pekárová, J., \& Moravčík, M. (2010). Electronic book of pedagogical research [online]. Bratislava: Univerzita Komenského. Retrieved August 2020, 16, from https:/ / www.e-metodologia.fedu.uniba.sk/.

[5] Kozarenko, M. O. (2019). Evaluation criteria for research work of students in a foreign language and the principles of their development. In: XLinguae, 12 (2), 195-209.

[6] Petlák, E. (2020). Mottivation in educational process. In: Slavonic Pedagogical Studies Journal. 9 (2), 106-114.

[7] Sirotová, M., \& Michvocíková, V. (2019). The importance of supervised practice teaching in university study of university students - future teachers of Slovak and foreign languages. In: XLinguae, 12 (3), $228-239$.

[8] Sirotová, M., Michvocíková, V., \& Host'ovecký, M. (2021). Serious Games in University Education of Future Teachers. Berlin: Peter Lang.

[9] Švec, Š., Gavora, P., Lapitka, M., Zelina, M., Kollárik, T., Maršálová, L., Ritomský, A., Benčo, J., Bajo, I., Semerádová, V., Kučera, M., Michálek, J., Skladaný, M., Piaček, J., Matulčík, J., \& Kompolt, P. (1998). The methodology of upbringing sciences. Bratislava: Iris. 